\title{
From who... to where? A geographical approach to peer-on-peer sexual abuse
}

Child protection systems in many western countries have developed with the aim of protecting young people from harm within families and by adults. But young people encounter harm in places outside of the home, and by peers. This raises a challenge for practitioners who must now consider new ways to protect young people from harm. In this article I focus on peer-on-peer sexual abuse. I reveal how child protection systems focussed on individuals - who? - fail to account for the places harm happens - where?

I bring together two theories - situated agency with contextual safeguarding. These provide a lens to understand how young people navigate unsafe places, and how practitioners understand and respond to the spatially contingent nature of abuse. I present data from meeting observations, focus groups and case reviews to argue that a geographical child protection model would equip practitioners with a preventative approach to protecting young people.

Keywords: child sexual abuse; peer-on-peer abuse; safeguarding; child protection; agency

\section{Dr Jenny Lloyd}

The International Centre: Researching child sexual exploitation, violence and trafficking

University of Bedfordshire

University Square

Luton

Bedfordshire

LU1 3JU

E: jenny.lloyd@beds.ac.uk

Twitter:@jennyalloyd

Orcid ID: 0000-0002-5114-2549

Disclosure statement: there are no conflicts of interest. 
Biographical note: Dr Jenny Lloyd is a Research Fellow at the University of Bedfordshire's International Centre: Researching child sexual exploitation, violence and trafficking. Her current research interests focus on peer-on-peer abuse, gendered violence and practice responses to extra-familial harm.

\section{Introduction}

Stories of widespread child sexual abuse (CSA) internationally have exposed the risks of abuse many young people face. Often, now, when we think about CSA, we might be drawn to thinking about specific towns and cities. Media interest into particular locations has reinforced these ideas about where we think abuse happens - and by whom. As Cream (1993, 237) suggests, these incidents often 'represent a moral panic with strong geographical connotations'. Previously research into the geography of CSA has prioritised prevalence and the individuals involved, perhaps with the assumption, or hope, these are isolated and extraordinary events - or people (Finkelhor et al. 2014). But abuse happens everywhere. Place has a greater role in the dynamics of abuse than we often assume. And while we might be questioning who this happens to (NSPCC 2018), it is time to ask bigger questions about where. In this article, I bring together a geographical model - situated agency (Panelli, Kraack, and Little 2005)- with a sociological model - contextual safeguarding (Firmin 2017a)- and apply these to explore child protection responses to peer-on-peer sexual abuse in the UK. I use this focus to argue that research and practice into peer-on-peer sexual abuse has developed through a narrow focus on individual children rather than harmful places. Drawing upon geographical literature on adult experiences of gendered abuse (Pain 1991, Valentine 1989) and work on children's use of space and safety (Spilsbury 2005, Vanderbeck and Johnson 2000) I propose a geographical child protection model, one that understands the role of place to harm, and works to protect young people - all young people wherever they are. 


\section{Peer-on-peer sexual abuse}

As children we are taught to fear the stranger. This fear has overshadowed much of how we think about CSA. But we now know harm can, and does, occur between young people who are known to each other. In this article, I focus on peer-on-peer sexual abuse, defined as:

\footnotetext{
Child sexual abuse perpetrated by other children and young people, often labelled harmful sexual behaviour, as well as peer-to-peer sexual coercion, which can often occur in the context of a relationship or friendship group. (Child Protection All-Party Parliamentary Group 2014, 8).
}

Peer-on-peer sexual abuse intersects with a range of different forms of abuse for example, serious youth violence, intimate partner violence, harmful sexual behaviour, bullying, child sexual exploitation and criminal exploitation for the purpose of drugs trafficking (Farrer \& Co and Firmin 2017). These may feature different methods or behaviours of abuse for example grooming, debt bondage, coercion, exchange, weapon carrying and violence as mechanisms of abuse. While this article focusses specifically on peer-on-peer sexual abuse, the findings reflect the intersection of these forms of harm.

In the UK and internationally a significant minority of children and young people experience peer-on-peer sexual abuse. One-third of sexual offences committed against children in the UK are instigated by another child (Hackett 2004). Studies into teenage relationship abuse reveal young people experience sexual coercion and harm within their relationships (Barter 2009). Research into adult CSA survivors found 66\% had experienced abuse from another child or young person rather than from an adult (Radford et al. 2011).

\section{Geographies of sexual abuse}

Beyond prevalence, what research into CSA indicates, is how peer-on-peer sexual abuse occurs in a range of places and that these locations influence how abuse manifests (Firmin 2017a). Considering this, the absence of geographical research in this area is surprising. In 
fact, there has been limited geographical work into all forms of CSA, including adult perpetration.Willis, Canavan, and Prior (2015) suggest the absence of human geography input within the field reflects and recreates the wider dynamics of abuse that silences survivors and prevents them disclosing.

Sexual violence itself has received geographical scrutiny. Pioneering work into the geographies of women's fear in the eighties and nineties exposed how fear of sexual violence shapes women's access to public space (Pain 1991, Valentine 1989). This work sparked geographical research into gendered violence. For example, highlighting how the assumption violent crime manifests as something happening outside the home, by strangers, has implications on how women use space. Feminist geographers argue that assuming violence happens outside the home overshadows the reality of harm within it, such as domestic violence (Warrington 2001). While this has inspired work into adult experiences of sexual violence, research into children and young people is lacking.

Instead, geographical work has questioned the spatialisation of fear in relation to children. Geographers have explored parent's concerns for safety outside the home (Valentine 1997). This work highlights how risk arises in different spaces (Pain 2004), and the ways parents' concerns for safety intersects with factors such as gender and age in addition to the local environment (Spilsbury 2005). Child abuse lurks as an absent presence within this work. Fear of public space personifies as a fear of the 'stranger' through reference to paedophiles or heightened anxiety of stranger danger (Matthews and Limb 1999). Yet, as within work on domestic violence, researchers have emphasised the contradiction in parents' fear for their children. While parents often fear for their children in public spaces, statistically they are more at risk within the home (Matthews and Limb 1999, 73). While this may be true, when young people do experience sexual violence outside the home, it is often by peers, not strangers. Furthermore, few geographical studies have actually engaged with abuse young 
people experience both within the home and outside. As Hörschelmann (2017) argues, this silencing problematically perpetuates normative constructions of the home as a safe space. Rather than considering the home as private place, she compels geographers to break down the binary between private and public in order to uncover how violence within the home shapes young people's experiences of other places.

Researchers highlight the need to account for young people's own experiences to work on safety, informed by temporal and spatial relations (Nayak 2003). For example how young people find safety for themselves in public spaces such as shopping malls (Vanderbeck and Johnson 2000). Where work has touched upon CSA, 'sex work' remains the focal point of analysis (Gibson 2009). Elsewhere research has explored what facilitates the sexual exploitation of children, for example child trafficking (Boyden and Howard 2013). Malcomson and Bradford's (2017) work on street children in Sierra Leone highlights how fear of social, cultural and material environments and experiences of sexual violence shape children's use of space. Yet despite these inputs into the field, few geographers have engaged specifically with CSA.

\section{From who...}

Traditional approaches to child protection in the UK often target individuals and the risks and vulnerabilities associated to them. This might include social work practitioners focussing on parental capacity to safeguard, one-to-one mentoring with young people, or at the extreme, relocation as a means to keep them safe. This means policy and practice has developed through a narrow focus on the young people themselves, their family and home, often lacking recognition of wider environmental aspects associated to the abuse they experience (Holland et al. 2010). Melrose (2013) suggests dominant CSA discourse individualises the problem promoting a limited focus on individual perpetrators and 'problematic' young people. This both ignores the social, economic and cultural structures facilitating exploitation, and young 
people's agency. In practice, individual approaches to adolescent harm result in individualised responses to abuse, for example assessment frameworks focussing on the individual 'victim' (Brodie 2013). Focussing on individual behaviour and experiences, as opposed to the contexts in which abuse occurs, overlooks the influence of gendered, classed and racialised power relations, and often fails to intervene with the perpetrators of harm in meaningful ways (Chung 2005).

In some instances, individualised responses, which prioritise individual choices and behaviour, contribute to problematic understandings that young people consent to their abuse. These narratives can be particularly damaging if practitioners cannot, or are not supported with, the framework to recognise the complexities of coercion and instead assume consent (Annitto 2011). Pearce (2013) argues consent must be understood within a system of exploitative contexts and relationships. She suggests:

a social model of consent would address the social and environmental features that impact on young people's ability to consent and help practitioners to assess the different ways that a young person's capacity to consent can be abused, exploited and manipulated (Pearce 2013, 53).

However, while professionals and researchers gradually recognise the need to develop a broader understanding of risk and vulnerability in young people's experiences, current approaches to child protection for adolescents remain focused on questions of who.

Recent inquiries into cases of sexual exploitation of young people in the UK noted a problematic focus on individuals rather than the environments where abuse occurs. The serious case review into child sexual exploitation (CSE) in Oxford, where a group of adult men sexually exploited children over 16 years, highlighted how lack of awareness and understanding of the communities and neighbourhoods young people lived within by professionals, reinforced judgments made about the young people which acted as a barrier to 
professionals preventing and stopping the exploitation happening (Bedford 2015). For example, labelling young people 'promiscuous', - often through gendered, racialised and classed stereotypes - resulted in victim-blaming through a false understanding of agency (Berelowitz et al. 2012). As such, as young people get older, judgements made about their individual (constrained) choices, behaviour and characteristics may overshadow the multiple ways environments, intersect to shape abuse. Trying to respond to the sexual abuse of young people by only focussing on individuals is like watching a football match where you only see the goalkeeper. It can be easy to focus on their actions - failing to save that goal - without understanding how all the players contributed. We need a system that can see the whole picture of what is going on - from the goalie to the strikers, the manager and the supporters.

\section{...to where?}

While the focus on individual young people experiencing abuse is not in itself a problem, young people experience harm in a range of environments beyond the home. Firmin, Warrington, and Pearce $(2016,2323)$ suggest 'when young people are sexually exploited within extra-familial environments, the environments themselves need to form part of the narratives of risk and response alongside accounts of individual and familial characteristics of those affected'. Here I bring together a geographical approach to agency - situated agency - (Panelli, Kraack, and Little 2005) with a sociological framework of child protection - contextual safeguarding (Firmin 2017b). In applying these two approaches to peer-on-peer sexual abuse, I use situated agency as a lens in which to understand the factors shaping how young people negotiate safe and unsafe environments. Contextual safeguarding extends this beyond individual young people, providing a framework and language practitioners and policy makers can understand in order to intervene in these places to make them safer

Panelli, Kraack and Little's (2005) model of situated agency highlights the intersecting factors women employ to navigate crime and fear. They suggest women engage 
a multi-dimensional approach to agency when negotiating fear and risk in different places: 'social contexts', 'personal biographies', 'spatial relations' and 'cultural discourses'. Following from van der Burgt (2015) I have adapted this below for young people.

\section{Insert Figure one here}

Figure one: Elements of agency (adapted from Panelli, Kraack and Little, 2005)

Panelli, Kraack and Little's (2005) work challenges narratives of victimhood in relation to women and their fear of crime. They argue that 'discursive, spatial and social relations are entwined in strategies that do not negate the existence of crime and emotions of fear and anxiety, but nevertheless forge ways to live with, and beyond, fear.' (p496). I apply situated agency here, in relation to peer-on-peer sexual abuse, to inform how practitioners account for young people's negotiation of safe and unsafe places. However, I propose that the application of geographical models does have the potential to diminish the existence of crime. I propose contextual safeguarding as a way to not only understand these dimensions but also extend this to engage within those spaces and actively change them.

If situated agency is a way to consider the dimensions of agency young people employ, contextual safeguarding is a model in which to explore how policy makers and practitioners engage with those dimensions. Contextual safeguarding is an approach to addressing the extra-familial nature of adolescent risk and vulnerability (Firmin 2017a). Firmin argues that responses to peer-on-peer abuse must recognise the contextual nature of abuse within different social fields. Based on Bourdieu's model of constructivist structuralism (Bourdieu 1990), contexts within a contextual safeguarding model, refer to the social fields in which young people spend time such as the home, peer group, school, neighbourhood and online. Each one of these contexts, or social fields, is imbued with social 
rules. When young people encounter different contexts they draw upon capital in order to navigate the rules at play (Firmin 2017a). Contextual Safeguarding is therefore concerned with the ability of policy and practice to recognise and engage with the contexts where harm occurs - either through providing young people with the capital to navigate those fields or changing the rules of play if they are seen to facilitate harm. This lens might be used to consider what information is gathered on an assessment of a child, the structure of meetings in which professionals discuss CSA cases or interventions into the neighbourhoods where young people encounter abuse (Anon 2018). In applying these two approaches together this article is primarily concerned with child protection practice, and how policy and practice can respond to young people's experiences of places outside the home.

Disciplines beyond geography have explored the role of space and place to CSA. For example, the influence of the physical landscape (Wortley and Smallbone 2006) or the impact of risk factors within peer groups, schools and neighbourhoods (Borduin, Schaeffer, and Heiblum 2009). Utilising a social ecological model scholars in criminology highlight how sexualised behaviour itself is not always a problem, but rather the context in which it occurs. As Smallbone, Rayment-Mchugh, and Smith $(2013,50)$ state: "The point is to understand how individual behaviour generally, and sexual offending behaviour specifically, is influenced by its social and immediate situational context". This is not to say all sexual offending is opportunistic or to absolve offenders of their crimes, but to highlight that there are opportunities to identify and intervene within these environments. This is particularly salient in cases of peer-on-peer sexual abuse when the victim/perpetrator binary is often not clear-cut (Pitts 2013). In bringing these two approaches together, I apply contextual safeguarding to situated agency, to understand practitioner responses to peer-on-peer sexual abuse. 


\section{Methodology}

The findings presented here are the result of two studies into child protection responses to peer-on-peer sexual abuse:

- Study one: Contextual safeguarding audits within three local authorities in England: Using a strength-based approach this study evaluated local multi-agency responses to peer-on-peer abuse, including child sexual exploitation, serious youth violence, teenage relationship abuse and criminal exploitation.

- Study two: Enablers and barriers to addressing harmful sexual behaviour in schools in four local authorities and seven education providers in England. The findings supported school and local authority inspectorates to identify systems, practices and cultures that prevent and aid responses to harmful sexual behaviour within schools (anon, 2018).

The findings presented here are primarily from the contextual safeguarding audits and complemented with evidence from a case review completed in the schools study. Each research project engaged a range of methodologies including:

- Observations of multi-agency meetings related to cases of peer-on-peer abuse. For example child sexual exploitation, harmful sexual behaviour, gangs and youth offending, school exclusion and domestic violence panels. The meetings brought together practitioners from social care, police, health and other agencies with the aim of managing risks associated with young people, sharing information and intelligence and developing interventions. An observation template was used to record details relating to the different contexts discussed: individuals, home, peers, school and neighbourhood and the target of interventions. 
- Case reviews of four cases of peer-on-peer sexual abuse held by social services and the youth offending service using a contextual case methodology (Firmin 2017b)

- Focus groups with practitioners to discuss responses to extra-familial risk and their perspective on system challenges and enablers to responding to peer-on-peer abuse more broadly.

- Focus groups with young people to discuss their experiences of safety in their local area/school. Young people were recruited by participating local authorities (study one) and schools (study two) based on their age and geographical location.

Participants were not selected based on previous experiences of abuse or particular vulnerabilities. Questions focussed on their feelings of safety and did not discuss personal experiences. In study one, focus groups were conducted at the local youth club and service. In study two focus groups were conducted at the school.

Each study involved a variety of methods, as displayed below:

\begin{tabular}{|l|c|c|}
\hline \multicolumn{1}{|c|}{ Method } & $\begin{array}{c}\text { Contextual safeguarding } \\
\text { audits }\end{array}$ & $\begin{array}{c}\text { Harmful sexual behaviour in } \\
\text { schools }\end{array}$ \\
\hline $\begin{array}{l}\text { Observation of multi-agency } \\
\text { meeting }\end{array}$ & 30 & 16 \\
\hline Observations within schools & 0 & 9 \\
\hline Review of policies and procedures & 88 & 3 \\
\hline Case review & 1 & 8 \\
\hline Review of behaviour logs & 0 & 16 \\
\hline Focus groups with practitioners & 3 & 17 \\
\hline Focus groups with young people & 2 & 65 \\
\hline
\end{tabular}

Table 1: Research methods

Ethics, analysis and limitations

This study received ethical approval from the [anon] in addition to approval from seven 
participating Local Safeguarding Children's Boards. Considering the sensitive nature of the study it was essential to account for the implications on the participants involved. Such considerations included confidentiality, consent, pathways for safeguarding concerns, security and data storage. The research team in both projects developed mechanisms to deal with disclosure (although no such instances arose). To ensure anonymity all names have been changed.

Within both projects a staged process was employed for the analysis of findings including, sense-checking with a local steering group, national research advisory group (study 2) and thematic coding using NVivo (both studies) for evidence of individual and contextual practice. Subsequent analysis took place using contextual safeguarding and situated agency as an analytical framework which considered the following:

- The extent to which child protection systems, processes and practice:

$\circ$ assessed and sought to prevent and intervene within the contexts - as opposed to only individuals- where young people experience peer-onpeer sexual abuse.

○ accounted for and acknowledged the intersection of young people's situated agency in relation to their pursuit of safety.

The focus of both projects, evidenced in the findings below, is upon child protection practice, as opposed to young people's personal experiences of peer-on-peer sexual abuse. As such, the findings presented here predominately focus on system and practitioner responses to peeron-peer sexual abuse and should not be used to define young people's experiences of abuse. While research on young people's experiences of sexual abuse remains a gap within geography such research would require a complex and careful methodological planning. 


\section{Findings}

In both studies observations of multi-agency meetings highlighted that sexual abuse happens in, or is facilitated by, a range of different contexts young people spend time in. Analysis therefore considered the extent to which practitioners recognised the multidimensional aspects of young people's safety within those contexts (situated agency), and the ability of child protection systems and practice to consider, and therefore intervene, with these contexts (contextual safeguarding). Here I demonstrate three aspects of child protection practicelanguage, the normalisation of abuse in places and through actions focussed on individuals.

\section{Language}

Observations, case reviews and focus groups highlighted the range of ways peer-on-peer sexual abuse was discussed. I observed the following terms in use by practitioners:

'Prostituting themselves' - to discuss three missing girls who were being sexually exploited within houses used for parties.

'Known to be unfaithful' - in regards to a young woman sexually exploited by members of a gang. ${ }^{1}$

'Savvy' - To explain why young women groomed for sexual exploitation are consenting.

These extracts highlight how practitioners focussed on young people's actions rather than the contexts they were navigating. This is further exemplified in one practitioner's view of sexual harm but was apparent throughout observations and case reviews:

\footnotetext{
We're not saying that we need to start making examples of girls and all of our girls need to be criminalised, but there also needs to be some context given to the fact that a lot of the girls we work with are fully aware of what they are doing. They are not all exploited to the point at which they have no choice in what they're doing. They're not. Okay, I
}

\footnotetext{
${ }^{1}$ This was challenged by the Chair of the meeting.
} 
think there is an element of brainwashing, which is probably not the right word but there is an element of brainwashing to them thinking that they're more a part of the process than they really are, and they're not being taken advantage of in terms of being transported from one place to another, but those girls are fully aware of the decision they make to be involved in some of that process. They are not always forced into it and I think that's the difficulty, is that a lot of the responses nationally are for girls who are genuinely forced into it without any say, without any awareness of what is going on. We have some very, very savvy girls who are $70 \%$ fully aware of what's going on and $30 \%$ don't really get how deep it is. They're the ones we don't have a response for. (Social worker, focus group with practitioners)

The extracts here highlight a bias towards young people's individual experiences as opposed to situating their harm in context. Language used to discuss young people reflected this preference, resulting in meetings focussing on young people's biographies - their family and living situation, attendance in school or missing episodes etc. - rather than other dimensions of situated agency. I highlight two implications of prioritising young people's biographies. Firstly, this individual focus often ignored broader contexts and the role of those instigating abuse. Secondly, practitioners failed to account for young people's agency.

In these extracts, the language used to describe the girls - all of which who had been sexually exploited - promoted a victim-blaming approach whereby they are, in part, blamed for their own abuse or seen as complicit in their abuse. As Randall (2010) suggests, victimblaming responses echo dominant gendered narratives of the 'ideal victim' whereby some women and girls are disqualified as 'legitimate' victims of sexual assault. Additionally, these words indicate a system which focusses on individuals rather than harmful contexts. In the extracts, the practitioners suggest sexually exploited girls are 'prostituting themselves', 'unfaithful' or 'savvy', ignoring the socio-cultural contexts these girls navigate daily, the restrictive rules at play in those settings and the role multiple young men had within their sexual exploitation. 
Secondly, the language used constructs the girls as active agents, minimising the impact of harm. Doing so replicates the gendered cultural discourses these meetings seek to disrupt and fails to acknowledge how young people employ a multi-dimensional approach to safety, making decisions to create (what they understand to be) safety for themselves. When we describe young people as savvy we ignore their situated and contextual agency and the complex and intersecting power discourses young people navigate. Young people operate within environments of constrained consent (Pearce 2013). I argue 'savviness', as described here, is the application of situated agency, place-based embodied knowledge developed through exposure to particular risks in particular places over time. Following from Cahill $(2000,252)$ savviness is a form of 'street literacy':

a way of constructing oneself in the process of understanding the world through interaction and experience in the environment. Street literacy is an interpretative framework that privileges experienced informal local knowledges that are grounded in personal experiences.

In suggesting young people are 'savvy', 'known to be unfaithful' or 'prostituting themselves' we ignore the multiple missed opportunities to provide other options to create safety for them. If language is a mirror to how we construct the world, these words reveal a system which priorities individuals and fails to consider and engage with the contexts - and other people in those contexts - where harm is occurring. Such discussions can, and do, have implications to the services young people receive. They also work to normalise abuse within certain places and with certain people.

\section{Normalisation of abuse}

While young people employ agency in order to keep themselves safe, problematic cultural and social discourses and systematic oppression shape their ability to do so effectively. In the following extract from a young person's focus group, Monika discusses her understanding of 
young people's experiences of sexual exploitation:

Monika: In gangs, there is a lot of sexual abuse, they'll use a girl, 'you have to have sex with me and all my friends'. So you'll be passed around and certain girls and boys, they're having sex at a young age, whether it's through giving up through the mouth, or whether it's through giving which is anal or whether it's normal sex. Anyway, there is a lot of girls being dragged into these nasty bushes and I don't think they're aware of what they're doing. (young people focus group)

It is clear from Monika that sexual abuse takes place in the local area, in specific locations and by other known peers. Monika highlights two aspects of situated agency here - cultural discourses and social contexts. Her comment highlights the necessity for holistic understandings of harm from a practice perspective. For example, within this cultural context, the view of women and girls- as sexual objects - facilitates their exploitation. Monika implies a certain level of consent within this. Peri explains the reasons for this below:

Peri: being a girl, sometimes it's not that easy [to say no to sex, carrying weapons and drugs] because you may love that person but if you have love for that person. 'you have love for me, you're going to do this, that and the other'. So at the same time, you're being dictated, you don't know what to do because you're scared at the same time. If he says, get down on your knees, do this, that and the other, you do it, which is wrong because you should have more self-respect for yourself and be like, no I'm not going to do that and learn to walk away. But they can be, drop this off, that's all they use girls for. (Focus group with young people)

Peri, when discussing her understanding of what happens to some young people, describes the complex power dynamics at play for girls in gang contexts. She recognises multiple factors make 'walking away' hard for girls. This is influenced, for example, by their position within a peer group, the value of girls within that context and their personal biographies. Young people's knowledge of, or very real experiences of sexual abuse and violence, shape their understanding of violence and abuse in different contexts. Furthermore, we must 
appreciate how young people's capacity to say no may be very limited if the alternative may be, and often is, considered to be worse.

When we don't think about places of harm, and the socio-cultural relations in those places, we can normalise abuse, preventing us from responding. Here two teachers talk about their school:

Dawn: I've literally watched it, 1,000 kids for an hour at lunchtime and if I could log the sexual assaults. You talk to them afterwards and the girls aren't taking it on board at all and the boys are having the time of their life. Interviewer: Can I just ask, when you say if I could log the sexual assaults, what is a barrier to that?

Sharon: Because if I talk to that girl and say, 'what he did to you was just wrong', [she says] 'no'. 'I'd like to take it further' but [she says] 'no, he didn't do anything wrong Interviewer:[what is the barrier?]

Sharon: They say they don't see anything wrong with it.

Dawn: I think sometimes the girls just want to seem a little bit popular as well. Sharon: They might say that but I would imagine most of them will go home and actually reflect on it and actually feel...

Dawn: It will be the frigid one who slaps someone's hand down and walks off. If everybody is letting the boys do it, who am I to stop them. So there is this new culture and it's horrible to see. You might see it walking down the street and think, what was going on there, but if you sit and watch them. They're not hiding anything. (Focus group with practitioners)

While both Dawn and Sharon recognise this behaviour is harmful, the assumption that it is a 'new culture' prevents her from responding and further normalises and condones sexual harm within the school. Dawn does challenge this, but through individual interventions, for example speaking to the girl (as opposed to the boys), rather than considering the behaviour as symptomatic of wider harmful gendered cultures throughout the school. By responding individually, she is unable to recognise and intervene in the contexts of harm, which would instead require a whole school approach. Furthermore, both Dawn and Sharon contribute to 
reinforcing the harmful cultural discourses facilitating harm, making it hard for young people to identify and disclose it - by suggesting some girls are 'frigid' and 'letting the boys do it'.

Challenging the normalisation of abuse in particular contexts requires practitioners to shift their focus from individual young people to the wider socio-cultural contexts where harm is facilitated. Within the research, cultural discourses, for example patriarchal constructions of the roles of women and girls, and social contexts, the relations between young people within peer groups were found to shape how harm and abuse manifests in different places and therefore how it was responded to . In the final example, by focussing on the young girl's behaviour as opposed to the harmful narratives within the school, or behaviour by the boys, the teachers fail to intervene in meaningful ways.

\section{Actions focussed on individuals}

When we focus on individuals rather than harmful places, interventions target only individual children. Observations highlighted the extent to which this was true. While practitioners considered multiple aspects relating to children's lives beyond their families, for example their peer groups or attendance at schools known for sexual violence, the interventions developed did not often consider these factors. The majority of interventions allocated were one-to-one services focussed on individuals or their families - for example, family support, mentoring, an individual CSA service or parenting classes. In one meeting, practitioners allocated services based on age of the young person rather than any other broader analysis of needs. In another meeting to review sexual exploitation, three different social workers presented cases including a park where CSA was happening. In response, these parks were then noted on a high-risk list for monitoring but there was no discussion about the park or why young people may be going there. In this final section I present one case which exemplifies how responses to peer-on-peer sexual abuse were individualised. The following 
summarises case notes held by a school: ${ }^{2}$

Annie (12) was forced into oral sex with another student (14) at a local park. Annie thought she was meeting a girl from a different school and arranged the meeting over social media. 'After the incident he called her a sket, there is no on-going relationship between the two young people'. Annie disclosed the incident as she heard it had happened to a year 7 from another school. 'The boy is on bail for 2 counts of rape and continues to attend the school'. 'Annie has put herself at risk and has experienced a situation that was unpleasant for her, and where she felt pushed (although not actually threatened) to give the boy oral sex'. (School case notes)

Actions:

- In school Annie will take part in lessons on consent.

- Parents to manage her use of social media.

- Ensure safety of young person in school.

- Annie to tell an adult immediately if the boy approaches her either through social media in person.

Case notes identified that the boy remained in school under staff supervision, in an area separate to Annie at break times, but could walk to and from school unescorted. Actions relating to his case included:

- Parents to manage social media

- Young person to talk to the nominated adult about any worries/ concerns

- Abide by bail conditions

- Work with school over any gradual re-introduction to break time and lunch time

- Parents to ensure he comes straight home from school

Individual responses to harm such as in the previous case, result in approaches to sexual abuse that do not recognise the role of socio-cultural and physical spaces to harm, do little to change the nature of those contexts or prevent further harm occurring. Two years before this an almost identical incident had occurred within the same park involving students from the same school. Nothing was done in this time to change the harmful contexts, for example the

\footnotetext{
${ }^{2}$ Direct quotes are indicated by quotation marks.
} 
attitudes of boys within the school to women and girls, the physical landscape of the park or the policies and procedures for managing sexual violence at school. These case notes highlight the pervasiveness of victim-blaming narratives focussed on individual actions. Annie's own behaviour - through her social media use and the allocation of a mentor - is targeted without a wider intervention into the park and school context associated to the abuse she experienced. Case notes evidenced a lack of contextualised thinking in relation to harm, and the resultant actions, endorsed a victim-blaming response, which failed to meaningfully engage with the broader harm that contributing to this assault and the previous one.

This case exemplifies a response following a violent sexual assault. While the type and locations of abuse varied between cases, the responses here typify interventions observed throughout the studies upon which this article is based. Observations and case reviews evidenced the need for a broader child protection system, one which both understands and engages in the multiple and situated dimensions young people employ to create safety and the contexts where harm occurs.

\section{Conclusion}

Historically, child protection in many countries including the UK, have been established to protect children against significant harm within their families (Parton 2014) - and by adults (Firmin 2017a). The challenge we face today is how to respond to the harm young people face outside of the home, by other young people. How can we create child protection systems that understand and engage with harmful contexts? Beyond naming locations of 'risk' this requires an interrogation of space, and social and cultural relations within that, outside the capabilities of the systems and structures many countries currently have to tackle harm. The findings I present here are part of a wider critique of child protection measures happening internationally (Munro 2011). I believe geographers are well placed to offer critical insights 
and practical recommendations in how to respond to some of these contemporary issues.

Geographical research into CSA has, to date, been limited. Without this input, responses to CSA have developed in absence of recognition of different places. Bringing together two approaches for understanding safety - situated agency and contextual safeguarding - .I propose a geographical model of child protection would support practitioners to both recognise and engage with, the socio-cultural contexts where harm occurs. This article responds to Willis, Prior and Canavan's $(2016,207)$ call to 'break the silence on CSA from within geography'. I suggest two further areas for development.

Firstly, the research presented here is from a body of work focussed on practitioner responses to adolescent harm. The issues raised here are not unique to the UK. Other countries, including the US, Australia, New Zealand and Canada, where child protection systems are focussed predominately on individuals and families, would benefit from a geographical approach to child protection. While there are movements to engage contextually-informed approaches to child protection internationally, these are in their infancy.

Secondly, there are implications of this work for children's geographies. A central theme throughout children's geographies has been the notion of agency and the need to champion children as competent decision makers (Ansell 2009, Jeffrey 2012). Vanderbeck (2008) suggests that through the preoccupation with agency scholars have been hesitant to deal with some of the 'bigger questions' of children's lives for fear of being viewed as 'antichild' - or perhaps anti-agency. When some of these 'bigger questions', such as child protection, have been discussed, scholars have raised how the systems and structures of child protection may be incompatible with the view of children as rights bearers and active agents (Todd 2012). Some suggest that engagement with child protection is conducive of, or legitimises, the encroachment of adult surveillance and restriction within children's lives 
(King 2007). Central to this debate is whether the aim of child protection is primarily concerned with punitive approaches to children and families, therefore legitimising surveillance, or the identification of systemic and structural factors undermining children's rights to safe and healthy lives. This not a reason to shy away researching child protection but an invitation to engage in productive debate with the aim of shaping and informing policy and practice (Smith 2004)

The current focus of child protection in the UK and in many countries internationally, is upon children and their families. Through contextual safeguarding I suggest a broadening of child protection away from individuals into the social settings and places outside of the home. Instead of assuming this means an encroachment of surveillance of children, I feel it would be productive to question the neoliberal assumption that the welfare state is always at odds with individual rights and freedoms (Archard 2014).

Secondly, work within children's geographies has focused on children's experiences of public space as restricted by adults (see Benwell2013 for a critique), and when harm is discussed, the assumption is of abuse by adults to children (Pain 2006). Instead the evidence I present here suggests that young people's experiences of public space are often shaped and influenced by other children. Focussing on peer-on-peer abuse requires us to consider children's agency, competency and decision making when it is young people - not adults that instigate the harm of others. There are vital opportunities for children's geographers to contribute here. For example, geographers would be well placed to discuss agency and competency from a criminal justice and child protection lens, particularly in relation to discrepancies in ages of such criminal responsibility, sexual consent and voting age internationally (Ruddick 2006).

Finally, we must acknowledge that children themselves, as the biggest victims of crime (Finkelhor and Dzuiba-Leatherman 1994), want access to increased protection. Beyond 
the discipline, children's agency and right to participate in decision making is informing policy and practice in relation to child protection including within the area of sexual violence (Warrington 2016). Children's geographers would be well positioned to challenge and engage in debates of child protection 'recognising young people as partners in (rather than simply recipients of) child protection' (Warrington 2012, 124)

\section{References}

Anon (2018)

Annitto, Megan. 2011. "Consent, Coercion, and Compassion: Emerging Legal Responses to the Commercial Sexual Exploitation of Minors." Yale Law \& Policy Review no. 30 (1): $1-70$.

Ansell, Nicola. 2009. "Childhood and the politics of scale: descaling children's geographies?" Progress in human geography no. 33 (2):190-209.

Archard, David. 2014. Children: Rights and childhood: Routledge.

Barter, Christine. 2009. "In the name of love: Partner abuse and violence in teenage relationships." British Journal of Social Work no. 39 (2):211-233.

Bedford, A. 2015. "Serious case review into child sexual exploitation in Oxfordshire: from the experiences of Children A, B, C, D, E, and F." Oxfordshire Safeguarding Children Board, Oxford.

Benwell, Matthew C. 2013. "Rethinking conceptualisations of adult-imposed restriction and children's experiences of autonomy in outdoor space." Children's Geographies no. 11 (1):28-43.

Berelowitz, Sue, Carlene Firmin, Gareth Edwards, and Sandra Gulyurtlu. 2012. "I thought I was the only one. The only one in the world." The Office of the Children's Commissioner's inquiry in to child sexual exploitation in gangs and groups: interim report (PDF). London: Office of the Children's Commissioner.

Borduin, Charles M, Cindy M Schaeffer, and Naamith Heiblum. 2009. "A randomized clinical trial of multisystemic therapy with juvenile sexual offenders: effects on youth social ecology and criminal activity." Journal of consulting and clinical psychology no. 77 (1):26.

Bourdieu, Pierre. 1990. In other words : essays towards a reflexive sociology. Cambridge: Polity.

Boyden, Jo, and Neil Howard. 2013. "Why does child trafficking policy need to be reformed? The moral economy of children's movement in Benin and Ethiopia." Children's Geographies no. 11 (3):354-368. doi: 10.1080/14733285.2013.817661.

Brodie, Isabelle. 2013. "Young People, Trafficking and Sexual Exploitation: A View from Scotland." In Critical Perspectives on Child Sexual Exploitation and Related Trafficking, 83-95. Springer.

Cahill, Caitlin. 2000. "Street literacy: Urban teenagers' strategies for negotiating their neighbourhood." Journal of youth studies no. 3 (3):251-277. 
Child Protection All-Party Parliamentary Group. 2014. Seminar Series on Child Sexual Abuse: Recommendations for the prevention of child sexual abuse and better support for victims. London.

Chung, Donna. 2005. "Violence, control, romance and gender equality: Young women and heterosexual relationships." Women's Studies International Forum no. 28 (6):445-455. doi: http://dx.doi.org/10.1016/j.wsif.2005.09.005.

Cream, J. 1993. "Child Sexual Abuse and the Symbolic Geographies of Cleveland." Environment and Planning D: Society and Space no. 11 (2):231-246. doi: $10.1068 / \mathrm{d} 110231$.

Farrer \& Co, and Carlene Firmin. 2017. Peer-on-peer abuse toolkit.

Finkelhor, David, and Jennifer Dzuiba-Leatherman. 1994. "Victimization of children." American Psychologist no. 49 (3):173.

Finkelhor, David, Anne Shattuck, Heather A Turner, and Sherry L Hamby. 2014. "The lifetime prevalence of child sexual abuse and sexual assault assessed in late adolescence." Journal of Adolescent Health no. 55 (3):329-333.

Firmin, C. 2017a. Abuse between Young People: A Contextual Account. Oxon: Routledge.

Firmin, Carlene. 2017b. "Contextualizing case reviews: A methodology for developing systemic safeguarding practices." Child \& Family Social Work.

Firmin, Carlene, Camille Warrington, and Jenny Pearce. 2016. "Sexual Exploitation and Its Impact on Developing Sexualities and Sexual Relationships: The Need for Contextual Social Work Interventions." British Journal of Social Work:bcw134.

Gibson, Chris. 2009. "Geographies of tourism: critical research on capitalism and local livelihoods." Progress in Human Geography no. 33 (4):527-534.

Hackett, Simon. 2004. What Works for Children and Young People with Harmful Sexual Behaviours? Ilford: Barnardos.

Holland, Sally, Stephen Burgess, Andy Grogan-Kaylor, and Jorge Delva. 2010. "Understanding neighbourhoods, communities and environments: New approaches for social work research." British journal of social work:bcq123.

Hörschelmann, Kathrin. 2017. "Violent Geographies of Childhood and Home: The Child in the Closet." In Geographies of Children and Young People: Conflict, Violence and Peace, edited by T. Skelton, C. Harker and K. Hörschelmann, 234-248. Singapore: Springer.

Jeffrey, Craig. 2012. "Geographies of children and youth II: Global youth agency." Progress in human geography no. 36 (2):245-253.

King, Michael. 2007. "The sociology of childhood as scientific communication: Observations from a social systems perspective." Childhood no. 14 (2):193-213.

Malcomson, Tim, and Simon Bradford. 2017. "Fearsome people and places, narratives of street and hideout children in Freetown, Sierra Leone." Children's Geographies:1-13.

Matthews, Hugh, and Melanie Limb. 1999. "Defining an agenda for the geography of children: review and prospect." Progress in human geography no. 23 (1):61-90.

Melrose, Margaret. 2013. "Young people and sexual exploitation: A critical discourse analysis." In Critical perspectives on child sexual exploitation and related trafficking, edited by Margaret. Melrose and Jenny. Pearce, 9-22. Hampshire: Palgrave Macmillan.

Munro, Eileen. 2011. The Munro review of child protection: Final report, a child-centred system. Vol. 8062: The Stationery Office.

Nayak, Anoop. 2003. "'Through children's eyes': childhood, place and the fear of crime." Geoforum no. 34 (3):303-315. doi: http://dx.doi.org/10.1016/S0016-7185(03)00003-4. 
NSPCC. Sexual abuse. Signs, indicators and effects 2018 [cited 25 Jan 2018. Available from https://www.nspcc.org.uk/preventing-abuse/child-abuse-and-neglect/child-sexualabuse/signs-symptoms-effects/.

Pain, Rachel. 1991. "Space, sexual violence and social control: integrating geographical and feminist analyses of women's fear of crime." Progress in Human Geography no. 15 (4):415-431. doi: 10.1177/030913259101500403.

Pain, Rachel. 2004. "Introduction: children at risk?" Children's Geographies no. 2 (1):65-67.

Pain, Rachel. 2006. "Paranoid parenting? Rematerializing risk and fear for children." Social \& Cultural Geography no. 7 (2):221-243. doi: 10.1080/14649360600600585.

Panelli, Ruth, Anna Kraack, and Jo Little. 2005. "Claiming space and community: Rural women's strategies for living with, and beyond, fear." Geoforum no. 36 (4):495-508.

Parton, Nigel. 2014. The politics of child protection: Contemporary developments and future directions: Palgrave Macmillan.

Pearce, Jenny. 2013. "A social model of 'abused consent'." In Critical perspectives on child sexual exploitation and related trafficking, edited by Margaret. Melrose and Jenny. Pearce, 52-68. Hampshire: Palgrave Macmillan.

Pitts, John. 2013. "Drifting into trouble: Sexual exploitation and gang affilitation." In Critical perspectives on child sexual exploitation and related trafficking, edited by Margaret Melrose and J. Pearce, 23-37. Hampshire: Palgrave Macmillan.

Radford, Lorraine, Susana Corral, Christine Bradley, Helen Fisher, Claire Bassett, Nick Howat, and Stephan Collishaw. 2011. "Child abuse and neglect in the UK today."

Randall, Melanie. 2010. "Sexual assault law, credibility, and "ideal victims": Consent, resistance, and victim blaming." Canadian Journal of Women and the Law no. 22 (2):397-433.

Ruddick, Susan. 2006. "Abnormal, the "new normal," and destabilizing discourses of rights." Public culture no. 18 (1):53-78.

Smallbone, Stephen, Susan Rayment-Mchugh, and Dimity Smith. 2013. "Youth sexual offending: Context, good-enough lives, and engaging with a wider prevention agenda." International journal of behavioral consultation and therapy no. 8 (3-4):49.

Smith, Fiona. 2004. "Is there a place for children's geographers in the policy arena?" Children's geographies no. 2 (1):157-161.

Spilsbury, James C. 2005. "'we don't really get to go out in the front yard'-children's home range and neighborhood violence." Children's Geographies no. 3 (1):79-99. doi: 10.1080/14733280500037281.

Todd, Liz. 2012. "Critical dialogue, critical methodology: bridging the research gap to young people's participation in evaluating children's services." Children's Geographies no. 10 (2):187-200.

Valentine, Gill. 1989. "The Geography of Women's Fear." Area no. 21 (4):385-390.

Valentine, Gill. 1997. "'Oh Yes I Can."“'Oh No You Can't": Children and Parents' Understandings of Kids' Competence to Negotiate Public Space Safely." Antipode no. 29 (1):65-89. doi: 10.1111/1467-8330.00035.

van der Burgt, Danielle. 2015. "Spatial avoidance or spatial confidence? Young people's agency in the active negotiation of risk and safety in public space." Children's Geographies no. 13 (2):181-195.

Vanderbeck, Robert M. 2008. "Reaching critical mass? Theory, politics, and the culture of debate in children's geographies." Area no. 40 (3):393-400.

Vanderbeck, Robert M, and Jr Johnson, James H. 2000. "" That's the only place where you can hang out": Urban young people and the space of the mall." Urban Geography no. $21(1): 5-25$. 
Warrington, C. 2012. "Partners in Care? Sexually exploited young people's inclusion and exclusion from decision making about safeguarding." In Critical perspectives on child sexual exploitation and trafficking, edited by M. Melrose and J. Pearce, 110- 124. Hampshire: Palgrave Macmillan.

Warrington, C. . 2016. Young person centred approaches in child sexual exploitation promoting participation and building self-efficacy: Frontline tool. . Dartington: Research in Practice.

Warrington, Molly. 2001. "I must get out': the geographies of domestic violence." Transactions of the Institute of British Geographers no. 26 (3):365-382. doi: 10.1111/1475-5661.00028.

Willis, Alette, Siobhan Canavan, and Seamus Prior. 2015. "Searching for safe space: the absent presence of childhood sexual abuse in human geography." Gender, Place \& Culture no. 22 (10):1481-1492. doi: 10.1080/0966369X.2015.1013456.

Willis, Alette, Seamus Prior, and Siobhan Canavan. 2016. "Spaces of dissociation: the impact of childhood sexual abuse on the personal geographies of adult survivors." Area no. 48 (2):206-212. doi: 10.1111/area.12254.

Wortley, Richard, and Stephen Smallbone. 2006. "Applying situational principles to sexual offenses against children." Crime prevention studies no. 19:7. 